\title{
Halloysite nanotube coatings suppress leukocyte spreading
}

\author{
Andrew D. Hughes ${ }^{1}$, Graham Marsh' ${ }^{2}$ Richard E. Waugh², David G. Foster ${ }^{3}$, and Michael R. \\ $\mathrm{King}^{1,}$, \\ ${ }^{1}$ Department of Biomedical Engineering, Cornell University, Ithaca, NY, 14853 \\ ${ }^{2}$ Department of Biomedical Engineering, University of Rochester, Rochester, NY, 14627 \\ ${ }^{3}$ Department of Chemical Engineering, University of Rochester, Rochester, NY, 14627
}

\begin{abstract}
The nanoscale topography of adhesive surfaces is known to be an important factor governing cellular behavior. Previous work has shown that surface coatings composed of halloysite nanotubes enhances the adhesion, and therefore capture, of rare target cells such as circulating tumor cells. Here, we demonstrate a unique feature of these coatings in its ability to reduce the adhesion of leukocytes and prevent leukocyte spreading. Surfaces were prepared with coatings of halloysite nanotubes and functionalized for leukocyte adhesion with E-selectin, and the dilution of nanotube concentration revealed a threshold concentration below which cell spreading became comparable with smooth surfaces. Evaluation of surface roughness characteristics determined that the average distance between discrete surface features correlated with adhesion metrics, with a separation distance of approximately $2 \mu \mathrm{m}$ identified as the critical threshold. Computational modeling of the interaction of leukocytes with halloysite nanotube coated surfaces of varying concentrations demonstrates that the geometry of the cell surface and adhesive counter-surface produce a significantly diminished effective contact area compared to a leukocyte interacting with a smooth surface.
\end{abstract}

\section{Keywords}

Nanotopography; leukocyte; cell spreading; cell adhesion; E-selectin; nanotube

The micro- and nanoscale topography of a biomaterial or tissue affect cell behavior independent of the chemistry of that surface. ${ }^{1,2}$ This has been known for more than two decades, however no consensus for how a cell is likely to behave on surfaces of different roughness has been reached. This is because cell behavior has been found to be highly variable depending on cell type, material type, surface feature dimensions and arrangement, etc. ${ }^{3,4,5}$ Nevertheless, the topographical nature of a surface has been shown to alter cell adhesion, ${ }^{6,7,8,9,10}$ motility, ${ }^{11}$ proliferation, ${ }^{12}$ activation, ${ }^{13}$ and differentiation. ${ }^{14}$ Micro- and nanostructured surfaces can additionally control the direction of movement of fibroblasts,

"Correspondence: mike.king@ cornell.edu.

CONFLICTS OF INTEREST The authors declare no conflicts of interest in this work. 
epithelial cells, and macrophages as well as the degree of adhesion of different cell types, including leukocytes. ${ }^{15}$

There are numerous stages in the adhesion of leukocytes as they home to sites of inflammation or infection. Selectin molecules are responsible for the first stage in adhesion within the bloodstream, in which cells tether and roll on the endothelial surface, followed by integrin activation and firm adhesion. ${ }^{16}$ What follows is a process of adhesion strengthening in which the cell flattens onto the surface and adhesion complexes are rearranged and the cytoskeleton is altered such that the cell is more firmly adhered to the surface and less likely to detach due to shear stress from the blood flow. ${ }^{17}$ These adhesion steps are followed by migration and extravasation. Adhesion strengthening is characterized by cell spreading, during which there is a marked increase in the contact area between the cell and the endothelium. The mechanical properties of the leukocyte play a significant role during the adhesion strengthening stage, in that the compliance of the leukocyte can increase cell adhesion by greater than 10 -fold in LFA-1/ICAM-1 mediated binding. ${ }^{18}$ Indeed, spreading is described as a distinct event in cell adhesion, and it is suggested that the kinetics and mechanisms required for adhesion and spreading are substantially different. ${ }^{19,} 20$

Cell spreading has been characterized as a very active process, initiated by dramatic surface receptor rearrangement. In particular, it has been shown that neutrophils spreading onto a surface coated with IL-8 redistribute adhesion receptor LFA-1 and chemokine receptors CXCR1 and CXCR2 from troughs in the plasma membrane to peripheral regions most closely apposed to the IL-8-coated surface. ${ }^{21}$ Spreading has been associated with one of several integrins binding to their ligands, followed by the generation of outside-in signaling cascades resulting in activation, migration, release of cytokines, and degranulation. ${ }^{22}$ Nanostructured materials are therefore of great interest to the field of biomaterials if they are able to modulate leukocyte adhesion and subsequent activation to prevent biofouling and inflammatory foreign body responses. ${ }^{23}$

Some of the innumerable applications of biomaterials lie in the field of cancer diagnostics. We have previously developed a device designed to positively select rare circulating tumor cells (CTC) from peripheral blood samples in vitro to facilitate downstream prognostic and drug susceptibility studies. ${ }^{24,25}$ The device is modeled on an inflamed postcapillary venule and functionalized with recombinant human E-selectin and antibodies against target cell receptors. E-selectin has been implicated in the metastatic spread of cancer cells through the circulatory system, ${ }^{26,27,28}$ and as such is used to rapidly capture flowing CTC within the sample. However, as E-selectin is primarily a physiological ligand for leukocyte adhesion, contamination of healthy leukocytes remains a challenge to device performance and acts to reduce the purity of isolated CTC samples. Purity can be improved with the incorporation of a coating of halloysite nanotubes (HNt), which was found to increase purity from $37 \%$ to $66 \% .{ }^{24}$ This discovery motivated the investigation of halloysite coatings as a bioactive material.

HNt are naturally occurring nanoparticles composed of aluminosilicate mineral having an outer diameter of $50-200 \mathrm{~nm}$, net negative charge, and variable length that can approach 1 $\mu \mathrm{m}$ (Fig. 1) ${ }^{29} \mathrm{HNt}$ have also been used to enhance the capture of cultured cancer cells, and 
we previously found that selectin molecules adsorb to the HNt coating and the increased surface area created by the HNt coating translated to increased selectin deposition, specifically showing a 108\% increase in adsorption when $6 \mu \mathrm{g} / \mathrm{mL}$ P-selectin was incubated on the surface and a 78\% \% increase in adsorption when $10 \mu \mathrm{g} / \mathrm{mL}$ P-selectin was incubated on the surface. We also demonstrated that the HNt coating overcame the innate physical limitation of microfluidic systems by penetrating the hydrodynamic lubrication layer. ${ }^{30}$

In this study, we have carried out an investigation of the ability of HNt coatings to modulate the adhesivity of leukocytes, initially discovered in prior CTC capture studies. It is established that HNt coatings reduce leukocyte adhesion and prevent leukocyte spreading, and that these behaviors are associated with surface roughness, and correlate with one roughness parameter in particular: the average distance between features. The concentration of $\mathrm{HNt}$ is varied to control the material parameters of the surface, and with cell behavior as the output it is possible to identify critical parameters that drive leukocyte adhesion. We finally employ a dynamic computational model of leukocyte spreading that confirms and explains these findings.

\section{RESULTS}

\section{Halloysite nanotubes}

Electron microscope investigation of halloysite nanotubes revealed that they are dispersed in solution individually or as small aggregates and exhibit a wide range of size (Fig. 1). It is also apparent that the nanotubes are hollow and primarily longer on the longitudinal axis.

\section{Halloysite nanotube coatings reduce leukocyte contact area}

The contact area between adherent leukocytes, isolated by RBC lysis, and the surface was measured at varying concentrations of HNt coating. Confocal microscopy was used to focus on the plane of contact. It was observed that at high concentrations of HNt, contact area remained constant at approximately $100 \mu \mathrm{m}^{2}$ per cell, and when the concentration of $\mathrm{HNt}$ in the coating solution was decreased below $1 \%(\mathrm{w} / \mathrm{v})$, the contact area increased to roughly twice the contact area per cell on a smooth surface (Fig. 2A). Variability in cell size was observed between donors, however a consistent trend in reduced contact area with increasing HNt concentration was observed for each donor. Sample size varied as well between donors, with a median of 86 cells analyzed on $13.3 \% \mathrm{HNt}$ per donor (range 35-281), 170 cells on $6.60 \% \mathrm{HNt}$ (range 121-210), 124 cells on 3.30\% $\mathrm{HNt}$ (range 64-343), 164 cells on $1.67 \%$ HNt (range 53-219), 164 cells on $0.825 \%$ (range 90-323), 277 cells on $0.412 \% \mathrm{HNt}$ (range 210-552), 232 cells on $0.206 \% \mathrm{HNt}$ (range 180-678), and 289 cells on the smooth surface (range 177-659). Observation of the mean contact area of all leukocytes revealed that there was a large reduction in the size of the contact region comparing $0.4 \%$ and $0.8 \% \mathrm{HNt}$. Serial micrographs captured in the $\mathrm{Z}$ plane demonstrate that leukocytes are flattened on the smooth surface (Fig. 2B) and remain spherical on surfaces coated with higher concentrations of $\mathrm{HNt}$ (Fig. 2C). Of note, previously reported antibody blocking and chelation studies have demonstrated that cellular adhesion to selectin-functionalized HNt-coated surfaces is entirely selectin-mediated. ${ }^{30}$ 


\section{Halloysite nanotube coating reduces number of adhering leukocytes}

Surfaces prepared in an identical manner to those used to determine contact area were assessed for cell count following $15 \mathrm{~min}$ of settling time, gentle wash, and fixation. Nuclei were stained to facilitate counting. It was observed that the number of adherent cells decreased with increasing HNt surface concentration, a similar trend to that observed for contact area (Fig. 3A). The reduction in adherent cell number is quite dramatic, as can be directly observed in representative micrographs (Fig. 3B and 3C). It is interesting to note that the most dramatic reduction in cell count was seen between $3.3 \%$ and $1.3 \% \mathrm{HNt}$, which differs from the behavior observed for contact area in which the greatest change was seen between $0.8 \%$ and $0.4 \% \mathrm{HNt}$.

\section{Mean distance between surface peaks correlates with cellular behavior}

Atomic force microscopy was used to determine the submicroscopic characteristics of the HNt coated surfaces. Surfaces were prepared in an identical manner to those used for studying cell behavior. Subsequent analysis of the HNt surfaces using the Image SXM software revealed that there were reductions in roughness $\left(\mathrm{R}_{\mathrm{a}}\right)$ and area ratio at the lowest concentration of HNt compared to higher concentrations of HNt, however no discernable trend continued after the lowest concentration of HNt (Table 1). Numerous line traces of height were generated from AFM scans and evaluated for the average distance between distinct surface features to establish an alternate measure of surface roughness. The mean distance between peaks varied from approximately 1 to $4 \mu \mathrm{m}$ and marked changes were measured at $\mathrm{HNt}$ concentrations below 1\% (Fig. 4). A separation distance of approximately $2 \mu \mathrm{m}$ was found to correlate with the change in cell spreading that was seen between 0.4 and $0.8 \%$ HNT. Surface zeta potential of coated surfaces was analyzed by dynamic light scattering using a zetasizer and it was determined that the HNt coating did not impact charge appreciably: $-43.5 \pm 1.5 \mathrm{mV}$ on the $13.3 \% \mathrm{HNt}$ surface versus $-38.4 \pm 3.3 \mathrm{mV}$ on the uncoated surface.

\section{Leukocyte adhesive behavior is consistent in whole blood}

To determine the behavior of leukocytes in more physiological applications, unprocessed heparinized whole blood was incubated on HNt-coated surfaces for $15 \mathrm{~min}$. Following a gentle wash, adherent cells were imaged to quantify contact area as before. Despite interdonor variability, it was determined that the adhesive behavior of leukocytes in the milieu of whole blood was very consistent with that seen for isolated cells in buffer as used in other experiments (Fig. 5). Again, analysis of the mean contact area showed significant increases in contact area at lower $\mathrm{HNt}$ concentrations.

\section{Computational modeling of leukocyte contact area is predictive of adhesive behavior}

Previous work by Bruel et al. identified a broad range of microvillus heights on leukocyte surfaces. ${ }^{31}$ Based on these data, Lomakina et al. developed a model of the leukocyte surface and the distribution of surface receptors in topographically-distinct regions, specifically on microvilli and intervening valleys. ${ }^{21}$ The inclusion of an adhesive surface with characteristic topography into this model (Fig. 6b) allowed for computational inspection of leukocyte adhesion onto model $\mathrm{HNt}$-coated surfaces with varying surface densities of $\mathrm{HNt}$ and 
subsequent measurement of the area of cell membrane that can be brought into direct physical contact with the surface (Fig. 6). For a smooth spherical cell, the maximum contact area occurred on a smooth surface and the contact area fell to a very low value upon incorporation of a few HNt onto the adhesive surface. It should be noted that due to the scale of the plot, the large surface contact of a smooth cell and smooth surface is out of range. As expected, as the number of HNt on the adhesive surface was increased, thereby increasing the surface area, the contact area of the smooth cell increased as well. However, this was not the case for a cell that possessed three microvilli in the contact region of its surface. Using the distribution of microvilli heights measured by Bruel et al. a precipitous decrease in contact area was observed similar to that seen with a smooth surface, however due to the geometry of the three microvilli this contact area remained at the minimum contact area and did not increase with increasing numbers of HNt on the adhesive surface. This trend is consistent with what was seen in spreading experiments (Fig. 1a) and provides a straightforward mechanism for this behavior. The mean number of peaks ( $250 \mu \mathrm{m}$ ) found in $2 \mu \mathrm{m}$-long segments was squared and used to estimate the number of $\mathrm{HNt}$ that are found in 2 $\mu \mathrm{m} \times 2 \mu \mathrm{m}$ areas of HNt coating. The average number of HNt in a $4 \mu \mathrm{m}^{2}$ area was found to increase dramatically with increasing HNt concentration, similar to the trend seen in the mean distance between peaks, and allows for rough correlation between the computational model, which has the number of HNt in such an area as the independent variable, with the experimental data for cell area (Table II).

\section{Halloysite nanotube coatings improve performance of microtube flow device}

A $300 \mu \mathrm{m}$ (i.d.) flow device was assembled to test the adhesion behavior of leukocytes with and without the HNt coating in a model biomedical device. Following 30 min of perfusion through the microtube device at a flow rate producing $2.5 \mathrm{dyn} / \mathrm{cm}^{2}$ of wall shear stress, it was observed that significantly more leukocytes adhered to the smooth surface regardless of the concentration of E-selectin used (Fig. 7b). Furthermore, at higher concentrations of Eselectin virtually all of the adherent cells in the smooth tube had spread flat onto the surface, while a negligible number of leukocytes spread onto the HNt surface (Fig. 7a). This is the case even at the highest concentrations of E-selectin studied. This indicates that the leukocytes are more firmly adhered to the smooth surface, and that a greater total area of the smooth surface is covered with leukocytes than on the HNt surface.

\section{DISCUSSION}

We demonstrate in this study that leukocytes spread on E-selectin coated substrates, and this behavior is largely abolished on nanostructured surfaces coated with halloysite nanotubes. The arrest of cell spreading occurred at a distinct concentration of $\mathrm{HNt}$, namely between $0.4 \%$ and $0.8 \% \mathrm{HNt}$, and this was a robust observation in that it was consistent between isolated cells (Fig. 2) and whole blood (Fig. 5). Furthermore, it was observed that even in the presence of inflammatory signals such as fMLP leukocyte spreading was prevented (Supplemental Figure 1). Usage of HNt was beneficial because it allowed for tuning of the surface roughness by simple dilution and is optically transparent when applied as a surface coating. 
Previous work by the King lab has characterized the HNt coating as having an enhancing effect on cell adhesion, resulting in increased protein adsorption and increased cellular adhesion both in terms of number and strength of carcinoma and leukemic cells. ${ }^{30}$ It was determined that the effect of the HNt coating was to increase selectin adsorption in addition to projecting adhesive ligands into the hydrodynamic lubrication layer to enhance capture of flowing cells. Here, we present a wholly distinct phenomenon for normal blood cells, in which the adhesion behavior of normal leukocytes is diminished, rather than enhanced, by the HNt coating.

It is interesting to note that the trend in cell contact area, the measure we use to quantify spreading, is also reflected in total cell adhesion counts (Fig. 3), however the shift in adhesion numbers occurs at a higher concentration of HNt. This is likely indicative of two simultaneous and separate actions of the HNt coating, making it less likely that leukocytes will adhere and also preventing leukocyte spreading, with the threshold values for these activities not necessarily being equivalent. The difference in threshold values is likely due to the prevalence and distribution of selectin ligands on the leukocyte surface and how this relates in space to the location of selectin on the HNt coating, and this is the subject of ongoing computational investigation.

A key feature of the HNt surface coating that appears to play an important role in cellular adhesive behavior is the lateral spacing of surface features on the contact plane (Fig. 4) rather than more conventional roughness measures. The roughness measurement $R_{a}$ is more of a quantification of the height of surface roughness features rather than the spacing of features, and it follows that $R_{a}$ is a gross evaluation of a surface and not necessarily representative of what an individual cell will experience when contacting a surface. These observations suggest that it is the number of nanotubes on the surface and the geometry of these tubes as defined by the dimensions of HNt that prevents leukocyte spreading. It is important to note that previous studies have provided evidence that selectin molecules adsorb to the HNt coating, therefore dilution of adhesive receptors on the surface is unlikely to explain a change in adhesion behavior.

Computational modeling of a surface coated with variable numbers of nanotubes and a cell possessing physiologically-relevant microvilli supports this idea (Fig. 6). Interestingly, the model also predicts that cells devoid of microvilli will experience increased surface contact with increasing HNt concentration, as was seen in previous studies. ${ }^{30}$ Investigation of the number of $\mathrm{HNt}$ within a defined area of the experimental HNt coating was not directly determined due to a lack of resolution with the AFM images that prohibited differentiation of individual nanoparticles, making direct correlation between the computational model and experimental results impossible. To overcome this, we analyzed the height profiles of the HNt coating along numerous randomly-placed line segments placed on AFM images of the $\mathrm{HNt}$ coating and squared the number of distinct peaks to estimate the number of distinct $\mathrm{HNt}$ within a $4 \mu \mathrm{m}^{2}$ area (Table II). This allowed for comparison of the computational model to experimental results in that the $0.206 \%$ HNt coating can be estimated to have 0.169 individual $\mathrm{HNt}$ in the cell contact region, the $1.65 \% \mathrm{HNt}$ coating has $4 \mathrm{HNt}$, etc. With this comparison it is evident that the computational model of cell contact area (Fig. 6) correlates quite well with the experimental measure of cell spreading (Fig.2), in that the model predicts 
that at HNt coatings that have 4 or more $\mathrm{HNt}$ in a $4 \mu \mathrm{m}^{2}$ area there will be minimal contact between the cell and the surface.

This study may be the first to show leukocyte spreading on E-selectin alone, in the absence of an activating cytokine such as IL-8. In some previous studies using micropipette aspiration to bring human neutrophils into contact with IL-8 or E-selectin coated microspheres, no significant spreading was found on E-selectin alone. ${ }^{32}$ The difference may be explained by the lack of centrifugation ${ }^{33}$ in micropipette experiments, where cells can be individually retrieved without centrifugation or erythrocyte lysis steps. Selectins are well known as receptors responsible for cell tethering and rolling. ${ }^{34}$ Selectins bind sialylated and fucosylated carbohydrates ${ }^{35}$ and it has recently been shown that core 1-derived o-glycans are required on ligands for E-selectin binding. ${ }^{36}$ Numerous leukocyte-bound ligands have been well described, including PSGL-1, ESL-1, CD44, CD43, Mac-1 $\left(a_{M} \beta_{2}\right)$, LFA-1 $\left(\alpha_{L} \beta_{2}\right)$, and MUC1. ${ }^{28,37,38,39,40,41}$ Furthermore, in murine models E-selectin ligand binding is known to activate leukocyte integrins, for example PSGL-1 and CD44 binding to E-selectin induce LFA-1 activation via tyrosine kinase Btk pathways. ${ }^{42,}, 43$ Therefore it is likely that the effect of the HNt coating is to prevent leukocyte activation due to restricted access to E-selectin moieties as illustrated by the computational modeling, and the absence of activated integrins forgoes cell spreading. Spreading is an energy-expensive process that requires extensive receptor and cytoskeletal rearrangement, ${ }^{21}$ and it follows that this process would be restricted to productive settings such as when a leukocyte is already tethered or rolling on endothelium via selectin bonds. Such activity by the HNt coating has yet to be fully realized and should be the focus of future work.

There is a general lack of data in the literature concerning the topography of the endothelial surface in vivo, ${ }^{44}$ doubtless due in part to technical challenges, so the relevance of this study to cellular behavior in vivo is presently impossible to determine. Microplicae are ridge-like folds found on the surface of epithelial cells that are anisotropic but exhibit similar spatial dimensions to the $\mathrm{HNt}$ coating ${ }^{45}$ and their biological function is not well understood. Microplicae have been identified on the surface of capillary endothelia in fowl, ${ }^{46}$ therefore it is possible to speculate on a role of nanotopography in leukocyte recruitment. It is also possible to consider the effect of inflammation on the topography of the endothelium, when vessels dilate and blood pressure increases. That leukocytes extravasate primarily in postcapillary venules is well known, and it is possible that endothelial smoothening aids this process. This too, however, is speculative at this time.

While the role of this study in the physiological setting is uncertain, its utility in vitro is clear. We demonstrated this with the example of cell capture in a microfluidic device (Fig. 7). Microfluidic devices are very prevalent in research and increasingly so in the clinic, and here we propose an efficient and inexpensive way to significantly reduce biofouling by leukocyte adhesion. This phenomenon, in conjunction with previous reports by our group in which non-leukocyte cell types (such as circulating tumor cells) display enhanced adhesion to HNt coatings highlight the synergistic activity of HNt coatings. 


\section{CONCLUSION}

In summary, we demonstrate a novel nanostructured coating that modulates the adhesive behavior of leukocytes in such as way that cell spreading is prevented. We extend this into a study of leukocyte spreading as a function of surface roughness by diluting the concentration of halloysite nanotubes on the surface and identify a threshold concentration of HNt that precludes cell spreading. Surface roughness characterization identified a metric of surface roughness that correlates with cell behavior, the mean distance between distinct surface features. Computational modeling of leukocyte contact with simulated HNt-coated surfaces demonstrates that the geometry of the leukocyte and the HNt-coated surface restricts access of the leukocyte to the surface to a very small effective contact area and agrees with experimental findings presented both here and in previous works. Finally, we demonstrate the utility of this coating in preventing leukocyte spreading and reducing leukocyte adhesion in a microfluidic example device.

\section{MATERIALS AND METHODS}

\section{Cells and reagents}

Peripheral whole blood was drawn from healthy volunteers after informed consent. Blood was collected into heparinized tubes (BD Biosciences, San Jose, CA). 10X erythrocyte lysis buffer was prepared as a solution of $1.5 \mathrm{M} \mathrm{NH}_{4} \mathrm{Cl}, 0.1 \mathrm{M} \mathrm{NaHCO} 3,0.01 \mathrm{M}$ disodium EDTA in distilled water. Ammonium chloride and sodium bicarbonate were purchased from SigmaAldrich (St. Louis, MO). Halloysite nanotubes were provided as a gift from NaturalNano, Inc. (Rochester, NY). Recombinant human E-selectin-IgG chimera was purchased from R\&D Systems (Minneapolis, MN). Paraformaldehyde was acquired from Electron Microscopy Sciences (Hatfield, PA). DAPI was purchased from Vector Laboratories (Burlingame, CA). Phosphate buffered saline (PBS), Hank's balanced salt solution (HBSS), and CellMask Deep Red plasma membrane stain were obtained from Life Technologies (Grand Island, NY). Blotting grade blocker nonfat dry milk was purchased from Quality Biological (Gaithersburg, MD). Calcium carbonate, poly-L-lysine $(0.1 \% \mathrm{w} / \mathrm{v}), 8$-well Flexiperm gaskets, and human serum albumin were obtained from Sigma-Aldrich. HEPES was purchased from ThermoFisher Scientific (Pittsburgh, PA).

\section{Preparation of surfaces}

Halloysite nanotube powder was dissolved in water to a concentration of $13.2 \% \mathrm{w} / \mathrm{v}$ and sonicated (Fisher Scientific) at 50\% load for $1 \mathrm{~min}$. Six serial 1:2 dilutions were then prepared with water, resulting in concentrations of $6.6,3.3,1.65,0.825,0.413$, and $0.206 \%$. Polystyrene microscope slides (VWR, Radnor, PA) were thoroughly cleaned with detergent in a sonicator, then rinsed and cleaned with $75 \%$ ethanol. 8-well flexiperm gaskets were placed on the slides and $250 \mu \mathrm{L} 0.2 \%$ poly-L lysine was incubated in each well for $5 \mathrm{~min}$. HNt solutions $(250 \mu \mathrm{L})$ were incubated within each well for 3 min, except for one that was filled with water to serve as a smooth surface. Each surface was gently rinsed twice with water, and then each well was filled with water and allowed to age for $24 \mathrm{~h} .250 \mu \mathrm{L}$ of 7.5 $\mu \mathrm{g} / \mathrm{mL}$ E-selectin was incubated on each surface for $2 \mathrm{~h}$ followed by a blocking incubation 
of 5\% milk protein for $1 \mathrm{~h}$. Finally, the selectin was activated by incubating each surface with PBS saturated with calcium carbonate.

\section{Preparation of leukocytes}

$10 \mathrm{X}$ erythrocyte lysis buffer (ELB) was prepared as a solution of $1.5 \mathrm{M} \mathrm{NH}_{4} \mathrm{Cl}, 0.1 \mathrm{M}$ $\mathrm{NaHCO}_{3}, 0.01 \mathrm{M}$ disodium EDTA in distilled water and sterilized by filtration. Working solutions of $1 \mathrm{X}$ ELB were prepared immediately prior to use using sterile distilled water and warmed to $37^{\circ} \mathrm{C}$. Fresh whole blood was diluted 1:10 with $1 \mathrm{X}$ ELB and placed on a rocker for $5 \mathrm{~min}$ at $37^{\circ} \mathrm{C}$. Cell suspensions were centrifuged at $1000 \mathrm{rpm}$ for $5 \mathrm{~min}$, washed once with HBSS, and resuspended in HBSS fortified with $\mathrm{CaCO}_{3}(2 \mathrm{mM})$, HEPES $(10 \mathrm{mM})$, and human serum albumin (5\%). Cells were counted using a hemacytometer and diluted to a concentration of 800,000 cells $/ \mathrm{mL}$.

\section{Leukocyte adhesion to HNt-coated surfaces}

200,000 cells in $250 \mu \mathrm{L}$ were applied to each well and allowed to settle and adhere for 15 min. Surfaces were gently washed twice with fortified HBSS and remaining cells were subsequently fixed with $4 \%$ paraformaldehyde for $30 \mathrm{~min}$. Cell membranes were stained with CellMask Deep Red for $10 \mathrm{~min}$ at room temperature and washed twice with PBS. DAPI mounting medium was applied to the slides after carefully removing the flexiperm gaskets and cover slips were placed on each slide. Formyl-methionyl-leucyl-phenylalanine (fMLP) (R\&D Systems, Minneapolis, MN) was added at a concentration of $1 \mathrm{nM}$ to the fortified HBSS 15 min prior to introducing leukocytes to coated surface.

In a separate set of experiments, unprocessed and undiluted whole blood was applied directly to each surface for 15 min, followed by washing, fixing, and staining as before.

\section{Analysis of cell spreading}

Slides were analyzed by confocal microscopy in the Cornell University Institute of Biotechnology imaging facility. Micrographs were captured at the cell-slide interface at ten random locations on each surface and saved for offline analysis. Contact area was measured using the ImageJ software by tracing around the periphery of the cell contact area, as indicated by the location of cell membrane labeled with CellMask. Cell contact area measurement were pooled for each donor to determine the mean contact area per cell along with the standard error of the mean (SEM), and then donor means were averaged and the SEM propagated to report the mean leukocyte contact area on each HNt concentration. Finally, statistical significance was calculated by two-way ANOVA using Graphpad Prism ${ }^{\circledR}$ to analyze the difference in contact area on each HNt coating.

\section{Quantification of adhering cells}

Surfaces and cells were prepared as described above for analysis of contact area. Following fixation of cells, nuclei were stained with DAPI to aid in quantification. Brightfield and fluorescent micrographs were acquired at 100X magnification at ten random locations on each surface. Cell count data was analyzed in the same way as that used for contact area data. 


\section{Surface roughness characterization}

HNt-coated surfaces were prepared as described above, and then dried in a vacuum desiccator following the overnight aging step. Slides were analyzed using a Vecco DI-3000 atomic force microscope, managed by the Cornell University Nanobiotechnology Center. $10 \times 10 \mu \mathrm{m}$ areas were scanned at three or more random locations on each surface. Image SXM was used to determine surface roughness $\left(\mathrm{R}_{\mathrm{a}}\right)$ and area ratio (surface area $\div$ planar area). Distance between peaks was determined by defining a peak as a surface feature that was distinct from its immediate surroundings by a height of $250 \mathrm{~nm}$. Line traces of topography were recorded at several random cross sections of each atomic force microscopy (AFM) image. Similarly, $2 \mu \mathrm{m}$ horizontal and vertical lines were drawn at random locations in the AFM images and the number of peaks, defined as above, was recorded based on the height profile of the surface across each line segment. The average number of peaks was then squared to estimate the number of $\mathrm{HNt}$ (i.e. distinct peaks) that are found in the average $2 \mu \mathrm{m} \times 2 \mu \mathrm{m}$ area. Statistical comparisons were made via symmetric Student's $t$ test in Graphpad Prism.

\section{Computational modeling of leukocyte contact area}

A detailed description of the development of the model can be found in reference 21 . Briefly, a cell surface was simulated with three microvilli of stochastic size within the range of $0-370 \mathrm{~nm}$ and probability distribution determined to agree closely with previously published observations of microvillus heights. A random distribution of $\mathrm{HNt}$ was populated in an area of $2 \times 2 \mu \mathrm{m}$ and a leukocyte with three microvilli was compared to a smooth cell by calculating the separation distance at each point. From that contact region, the total area within $70 \mathrm{~nm}$ of the surface was calculated as the contact area.

\section{Leukocyte adhesion within microtube flow device}

Microtube devices for cell capture were prepared as described previously ${ }^{30}$. Briefly, $50 \mathrm{~cm}$ lengths of $300 \mu \mathrm{m}$ i.d. Micro-renathane tubing (Braintree Scientific, Braintree, MA) were sterilized and coated with poly-L lysine and $6.6 \% \mathrm{HNt}$ in a similar procedure as that used to coat slides, and as described previously ${ }^{24}$. The smooth microtubes were coated with poly-L lysine with no HNt. Microtubes were incubated with $7.5 \mu \mathrm{g} / \mathrm{mL}$ E-selectin and blocked with $5 \%$ milk. Leukocytes at a concentration of $10^{6} / \mathrm{mL}$ suspended in fortified HBSS were perfused through the microtubes at a flow rate that produced a wall shear stress of 2.5 $\mathrm{dyn} / \mathrm{cm}^{2}$ for $30 \mathrm{~min}$. Microtube inlets were then transferred to cell-free buffer to wash off very loosely adherent cells, and then phase-contrast micrographs of 20 random locations along the length of each microtube were rapidly recorded with fluid flow maintained. Spread cells were identified visually by their spherical appearance and distinct edges. Statistical comparisons were carried out via symmetric Student's t test in Graphpad Prism.

\section{Transmission electron microscopy of halloysite nanotubes}

An aqueous dispersion of $\mathrm{HNt}$ was diluted with particle-free deionized water to a concentration suitable for well-dispersed particles in the electron microscope. A droplet of this dispersion (approximately $10 \mu \mathrm{L}$ ) was deposited on a commercial substrate (Ted Pella, $\mathrm{P} / \mathrm{N}$ 1824) composed of an ultrathin amorphous carbon film supported by a lacey carbon net 
mounted on a 400 mesh Cu TEM grid. The substrate was soaked with acetone for $30 \mathrm{~min}$ prior to preparation to render the surface more hydrophilic.

Transmission electron micrographs were recorded from the dried specimen using a FEI CM20ST TEM operated at $200 \mathrm{kV}$. The images were recorded on a Gatan Model 894 Ultrascan CCD camera with a $2048 \times 2048$ pixel CCD. The magnification was calibrated using the 0.25 and $0.1 \mu \mathrm{m}$ hole array from the "KMAG" standard manufactured for Kodak at Cornell University and certified by the National Physical Laboratory in Great Britain. The $2048 \times 2048$ pixel images were reduced to $1024 \times 1024$ pixel images with a bicubic interpolation.

\section{Supplementary Material}

Refer to Web version on PubMed Central for supplementary material.

\section{Acknowledgments}

This work was supported by a grant from the National Institutes of Health (HL018208) to M.R.K. and R.E.W., and a National Science Foundation Graduate Research Fellowship to A.D.H. (DGE-0707428).

\section{References}

1. Wojciak-Stothard B, Madeja Z, Korohoda W, Curtis A, Wilkinson C. Activation of macrophage-like cells by multiple grooved substrata. Topographical control of cell behaviour. Cell Biol Int. 1995; 19(6):485-90. [PubMed: 7640662]

2. Curtis A, Wilkinson C. Topographical control of cells. Biomaterials. 1997; 18(24):1573-83. [PubMed: 9613804]

3. Flemming RG, Murphy CJ, Abrams GA, Goodman SL, Nealey PF. Effects of synthetic micro- and nano-structured surfaces on cell behavior. Biomaterials. 1999; 20(6):573-88. [PubMed: 10213360]

4. Yim EK, Leong KW. Significance of synthetic nanostructures in dictating cellular response. Nanomedicine. 2005; 1(1):10-21. [PubMed: 17292053]

5. Lim JY, Donahue HJ. Cell sensing and response to micro- and nanostructured surfaces produced by chemical and topographic patterning. Tissue Eng. 2007; 13(8):1879-91. [PubMed: 17583997]

6. Schmidt JA, von Recum AF. Macrophage response to microtextured silicone. Biomaterials. 1992; 13(15):1059-69. [PubMed: 1493189]

7. Dalby MJ, Giannaras D, Riehle MO, Gadegaard N, Affrossman S, Curtis AS. Rapid fibroblast adhesion to $27 \mathrm{~nm}$ high polymer demixed nano-topography. Biomaterials. 2004; 25(1):77-83. [PubMed: 14580911]

8. Karuri NW, Liliensiek S, Teixeira AI, Abrams G, Campbell S, Nealey PF, Murphy CJ. Biological length scale topography enhances cell-substratum adhesion of human corneal epithelial cells. J Cell Sci. 2004; 117(Pt 15):3153-64. [PubMed: 15226393]

9. Curtis AS, Gadegaard N, Dalby MJ, Riehle MO, Wilkinson CD, Aitchison G. Cells react to nanoscale order and symmetry in their surroundings. IEEE Trans Nanobioscience. 2004; 3(1):61-5. [PubMed: 15382646]

10. Martines E, McGhee K, Wilkinson C, Curtis A. A parallel-plate flow chamber to study initial cell adhesion on a nanofeatured surface. IEEE Trans Nanobioscience. 2004; 3(2):90-5. [PubMed: 15382740]

11. Yim EK, Reano RM, Pang SW, Yee AF, Chen CS, Leong KW. Nanopattern-induced changes in morphology and motility of smooth muscle cells. Biomaterials. 2005; 26(26):5405-13. [PubMed: 15814139] 
12. den Braber ET, de Ruijter JE, Ginsel LA, von Recum AF, Jansen JA. Quantitative analysis of fibroblast morphology on microgrooved surfaces with various groove and ridge dimensions. Biomaterials. 1996; 17(21):2037-44. [PubMed: 8902235]

13. Ainslie KM, Tao SL, Popat KC, Daniels H, Hardev V, Grimes CA, Desai TA. In vitro inflammatory response of nanostructured titania, silicon oxide, and polycaprolactone. J Biomed Mater Res A. 2009; 91(3):647-55. [PubMed: 18988278]

14. Wall I, Donos N, Carlqvist K, Jones F, Brett P. Modified titanium surfaces promote accelerated osteogenic differentiation of mesenchymal stromal cells in vitro. Bone. 2009; 45(1):17-26. [PubMed: 19332166]

15. Eriksson C, Lausmaa J, Nygren H. Interactions between human whole blood and modified TiO2surfaces: influence of surface topography and oxide thickness on leukocyte adhesion and activation. Biomaterials. 2001; 22(14):1987-96. [PubMed: 11426876]

16. Langer HF, Chavakis T. Leukocyte-endothelial interactions in inflammation. J Cell Mol Med. 2009; 13(7):1211-20. [PubMed: 19538472]

17. Ley K, Laudanna C, Cybulsky MI, Nourshargh S. Getting to the site of inflammation: the leukocyte adhesion cascade updated. Nat Rev Immunol. 2007; 7(9):678-89. [PubMed: 17717539]

18. Wojcikiewicz EP, Zhang X, Chen A, Moy VT. Contributions of molecular binding events and cellular compliance to the modulation of leukocyte adhesion. J Cell Sci. 2003; 116(Pt 12):2531-9. [PubMed: 12734401]

19. Pierres A, Benoliel AM, Bongrand P. Cell fitting to adhesive surfaces: A prerequisite to firm attachment and subsequent events. Eur Cell Mater. 2002; 3:31-45. [PubMed: 14562252]

20. Robert P, Touchard D, Bongrand P, Pierres A. Biophysical description of multiple events contributing blood leukocyte arrest on endothelium. Front Immunol. 2013; 4:108. [PubMed: 23750158]

21. Lomakina EB, Marsh G, Waugh RE. Cell surface topography is a regulator of molecular interactions during chemokine-induced neutrophil spreading. Biophys J. 2014; 107(6):1302-12. [PubMed: 25229138]

22. Abram CL, Lowell CA. The ins and outs of leukocyte integrin signaling. Annu Rev Immunol. 2009; 27:339-62. [PubMed: 19302044]

23. Voskerician G, Shive MS, Shawgo RS, von Recum H, Anderson JM, Cima MJ, Langer R. Biocompatibility and biofouling of MEMS drug delivery devices. Biomaterials. 2003; 24(11): 1959-67. [PubMed: 12615486]

24. Hughes AD, Mattison J, Western LT, Powderly JD, Greene BT, King MR. Microtube device for selectin-mediated capture of viable circulating tumor cells from blood. Clin Chem. 2012; 58(5): 846-53. [PubMed: 22344286]

25. Hughes AD, Mattison J, Powderly JD, Greene BT, King MR. Rapid isolation of viable circulating tumor cells from patient blood samples. J Vis Exp. 2012; (64):e4248. [PubMed: 22733259]

26. Hiratsuka S, Goel S, Kamoun WS, Maru Y, Fukumura D, Duda DG, Jain RK. Endothelial focal adhesion kinase mediates cancer cell homing to discrete regions of the lungs via E-selectin upregulation. Proc Natl Acad Sci U S A. 2011; 108(9):3725-30. [PubMed: 21321210]

27. Orr FW, Lee J, Duivenvoorden WC, Singh G. Pathophysiologic interactions in skeletal metastasis. Cancer. 2000; 88(12 Suppl):2912-8. [PubMed: 10898334]

28. Geng Y, Yeh K, Takatani T, King MR. Three to Tango: MUC1 as a Ligand for Both E-Selectin and ICAM-1 in the Breast Cancer Metastatic Cascade. Front Oncol. 2012; 2:76. [PubMed: 22866263]

29. Levis SR, Deasy PB. Characterisation of halloysite for use as a microtubular drug delivery system. Int J Pharm. 2002; 243(1-2):125-34. [PubMed: 12176301]

30. Hughes AD, King MR. Use of naturally occurring halloysite nanotubes for enhanced capture of flowing cells. Langmuir. 2010; 26(14):12155-64. [PubMed: 20557077]

31. Bruehl RE, Springer TA, Bainton DF. Quantitation of L-selectin distribution on human leukocyte microvilli by immunogold labeling and electron microscopy. J Histochem Cytochem. 1996; 44(8): 835-44. [PubMed: 8756756]

32. Beste MT, Lomakina EB, Hammer DA, Waugh RE. Immobilized IL-8 Triggers Phagocytosis and Dynamic Changes in Membrane Microtopology in Human Neutrophils. Annals of biomedical engineering. 2015 
33. Lee D, King MR. Shear-induced capping of L-selectin on the neutrophil surface during centrifugation. Journal of immunological methods. 2007; 328(1-2):97-105. [PubMed: 17915247]

34. Springer TA. Traffic signals for lymphocyte recirculation and leukocyte emigration: the multistep paradigm. Cell. 1994; 76(2):301-14. [PubMed: 7507411]

35. Kansas GS. Selectins and their ligands: current concepts and controversies. Blood. 1996; 88(9): 3259-87. [PubMed: 8896391]

36. Yago T, Fu J, McDaniel JM, Miner JJ, McEver RP, Xia L. Core 1-derived O-glycans are essential E-selectin ligands on neutrophils. Proc Natl Acad Sci U S A. 2010; 107(20):9204-9. [PubMed: 20439727]

37. Katayama Y, Hidalgo A, Chang J, Peired A, Frenette PS. CD44 is a physiological E-selectin ligand on neutrophils. J Exp Med. 2005; 201(8):1183-9. [PubMed: 15824084]

38. Xia L, Sperandio M, Yago T, McDaniel JM, Cummings RD, Pearson-White S, Ley K, McEver RP. P-selectin glycoprotein ligand-1-deficient mice have impaired leukocyte tethering to E-selectin under flow. J Clin Invest. 2002; 109(7):939-50. [PubMed: 11927621]

39. Matsumoto M, Shigeta A, Miyasaka M, Hirata T. CD43 plays both antiadhesive and proadhesive roles in neutrophil rolling in a context-dependent manner. J Immunol. 2008; 181(5):3628-35. [PubMed: 18714037]

40. Hidalgo A, Peired AJ, Wild MK, Vestweber D, Frenette PS. Complete identification of E-selectin ligands on neutrophils reveals distinct functions of PSGL-1, ESL-1, and CD44. Immunity. 2007; 26(4):477-89. [PubMed: 17442598]

41. Crutchfield KL, Shinde Patil VR, Campbell CJ, Parkos CA, Allport JR, Goetz DJ. CD11b/CD18coated microspheres attach to E-selectin under flow. J Leukoc Biol. 2000; 67(2):196-205. [PubMed: 10670580]

42. Mueller H, Stadtmann A, Van Aken H, Hirsch E, Wang D, Ley K, Zarbock A. Tyrosine kinase Btk regulates E-selectin-mediated integrin activation and neutrophil recruitment by controlling phospholipase C (PLC) gamma2 and PI3Kgamma pathways. Blood. 2010; 115(15):3118-27. [PubMed: 20167705]

43. Yago T, Shao B, Miner JJ, Yao L, Klopocki AG, Maeda K, Coggeshall KM, McEver RP. E-selectin engages PSGL-1 and CD44 through a common signaling pathway to induce integrin alphaLbeta2mediated slow leukocyte rolling. Blood. 2010; 116(3):485-94. [PubMed: 20299514]

44. Park SW, Intaglietta M, Tartakovsky DM. Impact of endothelium roughness on blood flow. J Theor Biol. 2012; 300:152-60. [PubMed: 22300799]

45. Andrews PM. Microplicae: characteristic ridge-like folds of the plasmalemma. J Cell Biol. 1976; 68(3):420-9. [PubMed: 828906]

46. Kiama SG, Bhattacharjee J, Maina JN, Weyrauch KD. Surface specialization of the capillary endothelium in the pecten oculi of the chicken, and their overt roles in pectineal haemodynamics and nutrient transfer to the inner neural retina. Acta Biol Hung. 1997; 48(4):473-83. [PubMed: 9847460] 


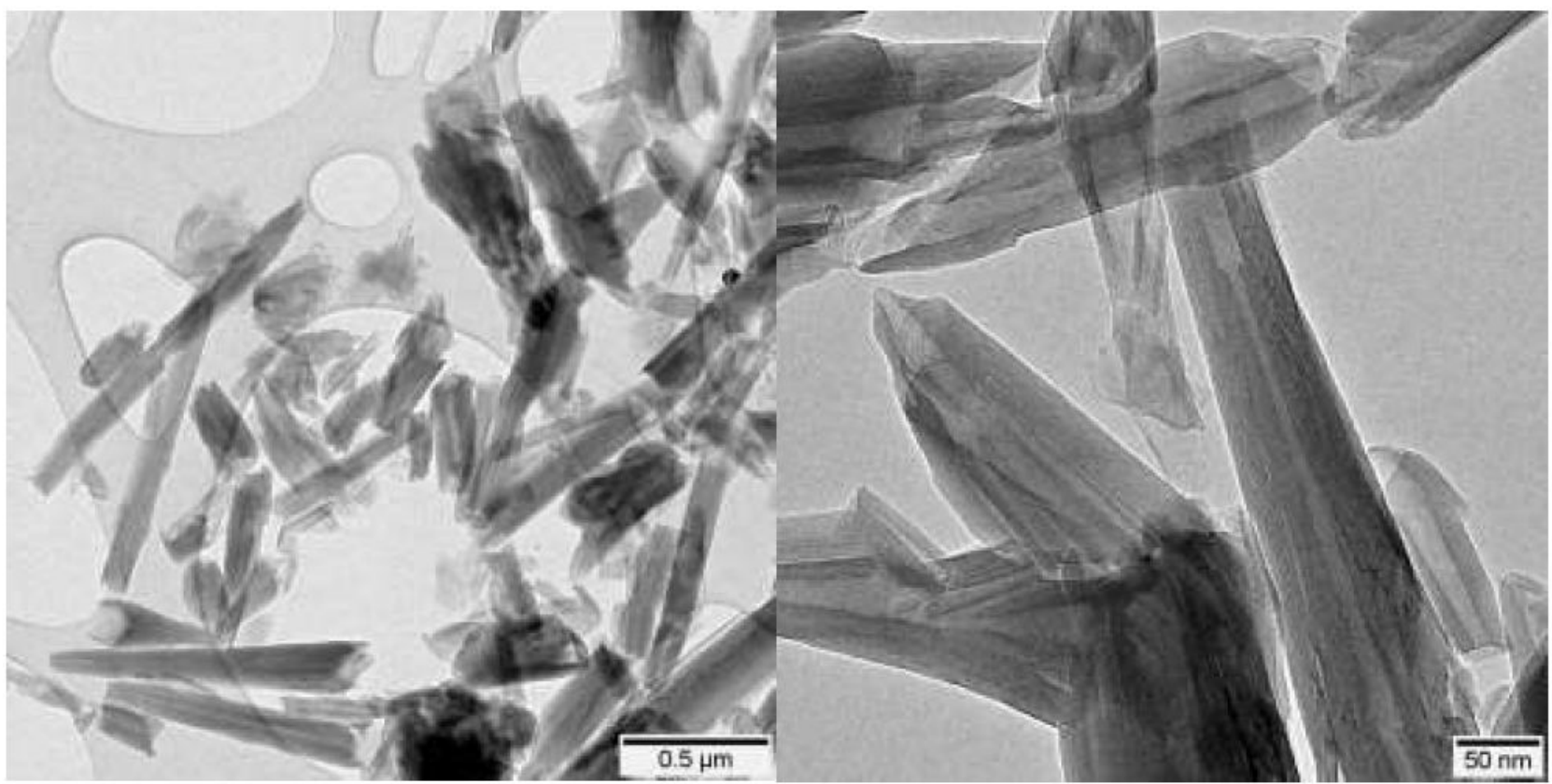

Figure 1.

Transmission electron microscopy of halloysite nanotubes. Scale bars indicate $500 \mathrm{~nm}$ (left) and $50 \mathrm{~nm}$ (right). 

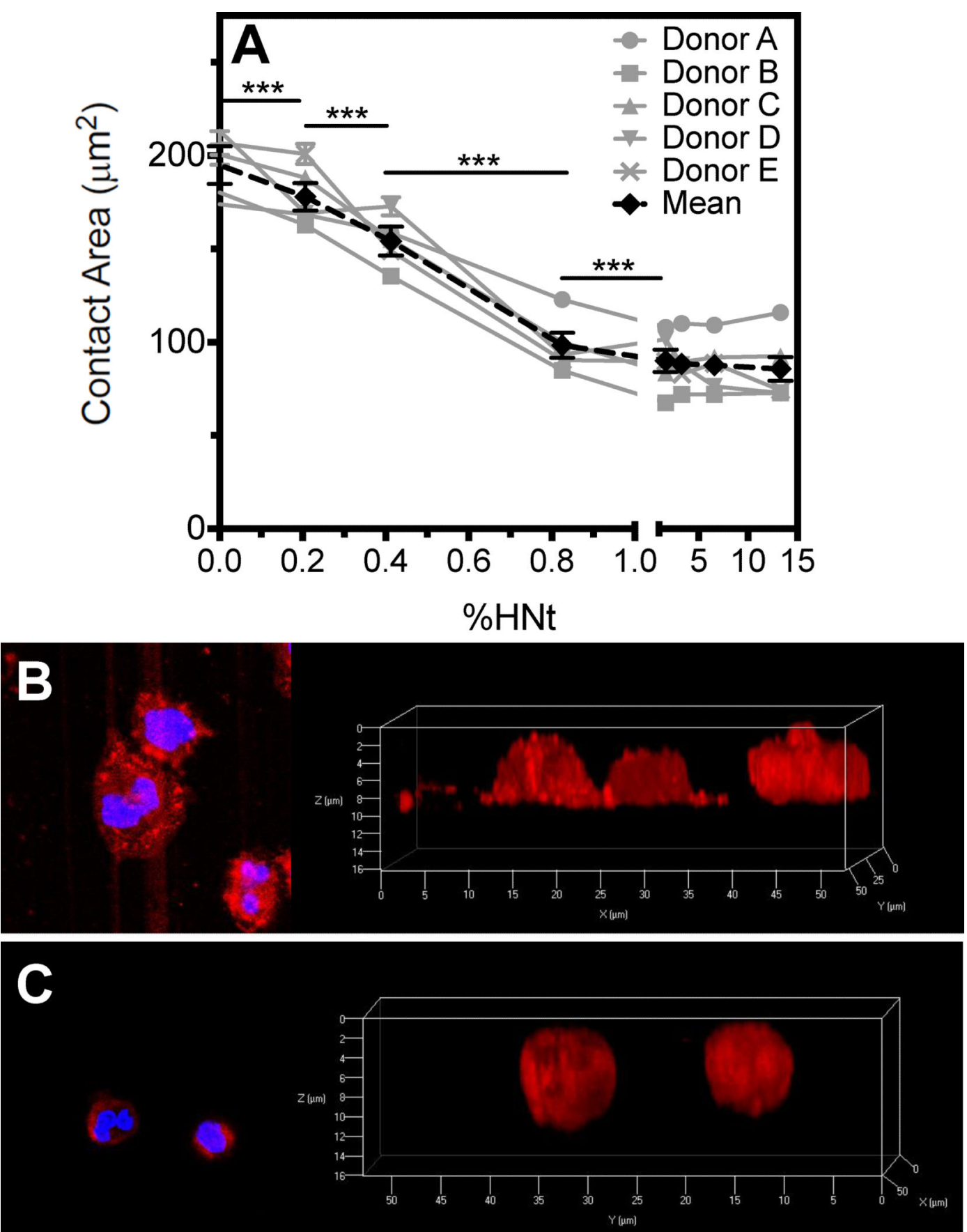

Figure 2.

Leukocyte contact area, as defined by the region of cell membrane that is visualized closest to the surface by confocal microscopy, decreases with increasing HNt surface concentration, as identified by cell area at the plane of the surface (A). X-axis is broken at $1.0 \%$. Cells on the smooth surface appear spread and flattened (B) compared to the more spherical cells bound to a surface coated with $13.3 \% \mathrm{HNt}(\mathrm{C})$. In panels B and C the image on the right is the digital reconstruction of Z-stacks acquired by confocal microscopy and is the view of the 
image on the left as seen from the bottom. $* * * \mathrm{P}<0.001$. Error bars represent SEM, however statistical significance was calculated by two-way ANOVA. 

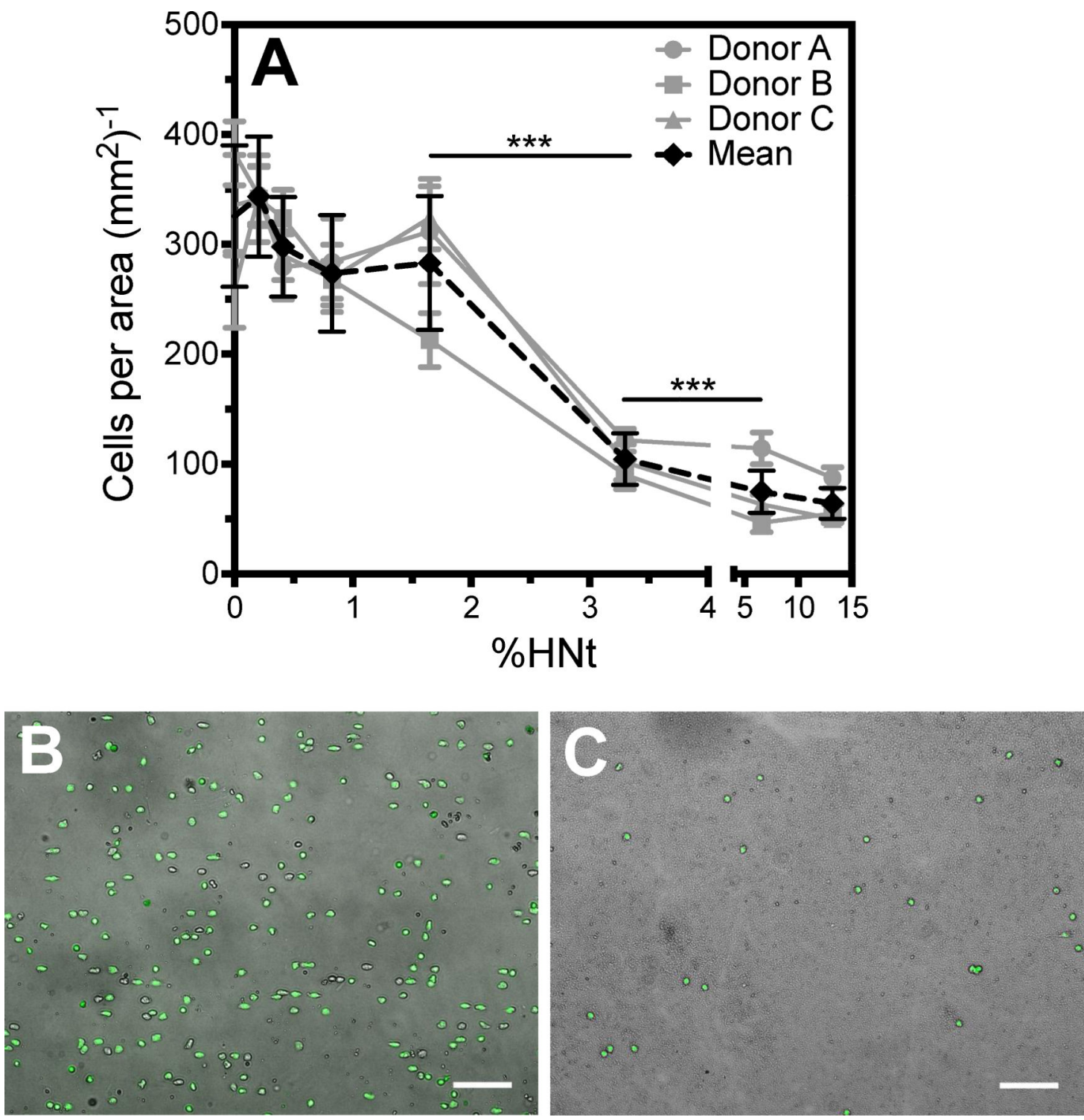

Figure 3.

The number of adherent leukocytes is reduced on high concentrations of $\mathrm{HNt}(\mathrm{A})$. X-axis is broken at $5.0 \%$. Representative images demonstrate that there are more leukocytes bound to the smooth surface (B) than to the $13.3 \% \mathrm{HNt}$ surface (C). Scale bars indicate $100 \mu \mathrm{m}$ and cells are readily identified by DAPI staining of their nuclei (green). $* * \mathrm{P}<0.01$. Error bars represent SEM, however statistical significance was calculated by two-way ANOVA. 

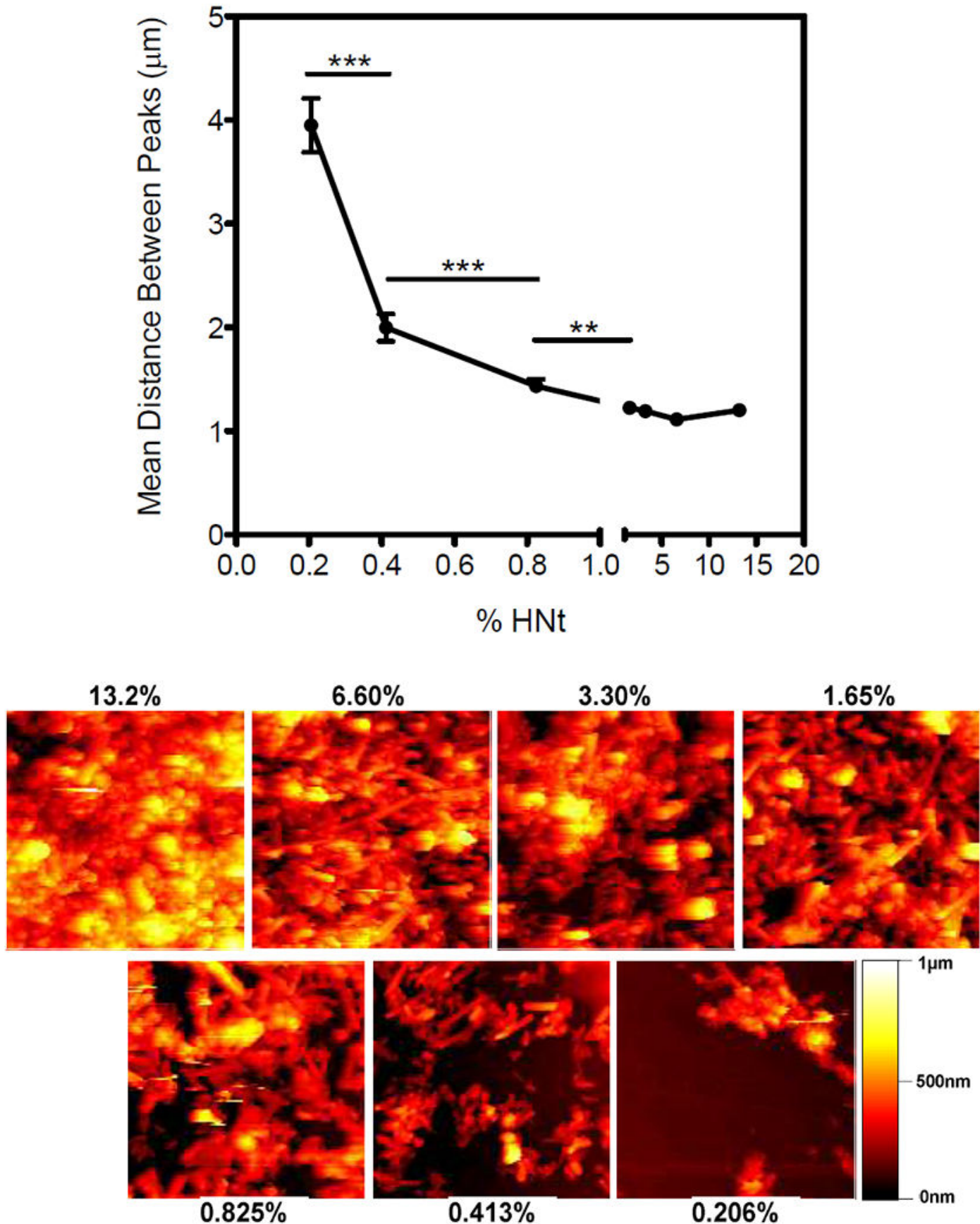

Figure 4.

Analysis of the lateral spacing of surface features created by the HNt coating, obtained from atomic force microscopy (AFM) of the HNt coatings, reveals that there is a significant reduction in spacing with increasing concentration of HNt (upper pane). All AFM images are $5 \times 5 \mu \mathrm{m} . * * \mathrm{P}<0.01, * * * \mathrm{P}<0.001$. 


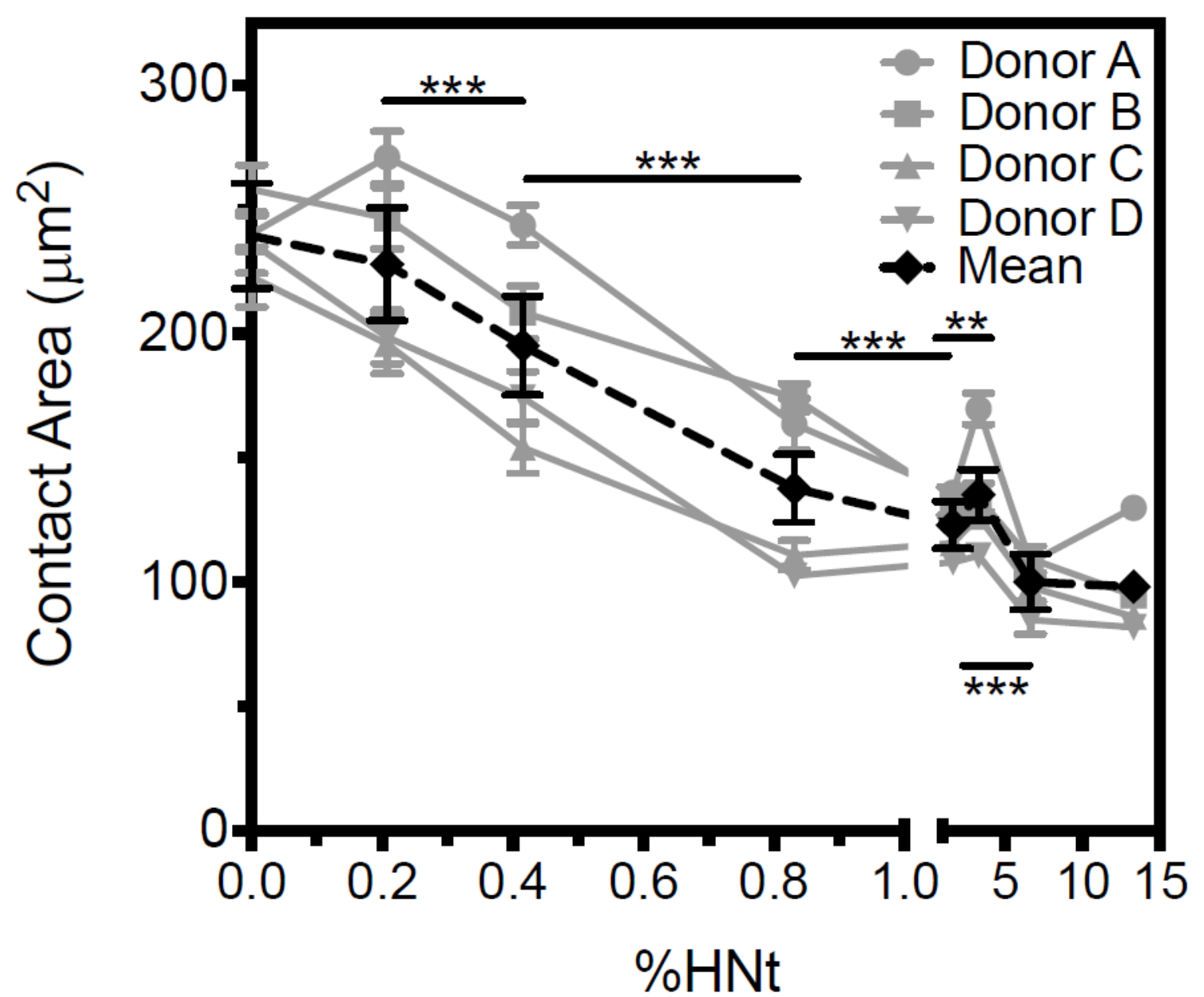

Figure 5.

Leukocyte contact area decreases with increasing HNt surface concentration when incubated on surfaces in whole blood. $* \mathrm{P}<0.05$. Error bars represent $\mathrm{SEM}$, however statistical significance was calculated by two-way ANOVA. 
A

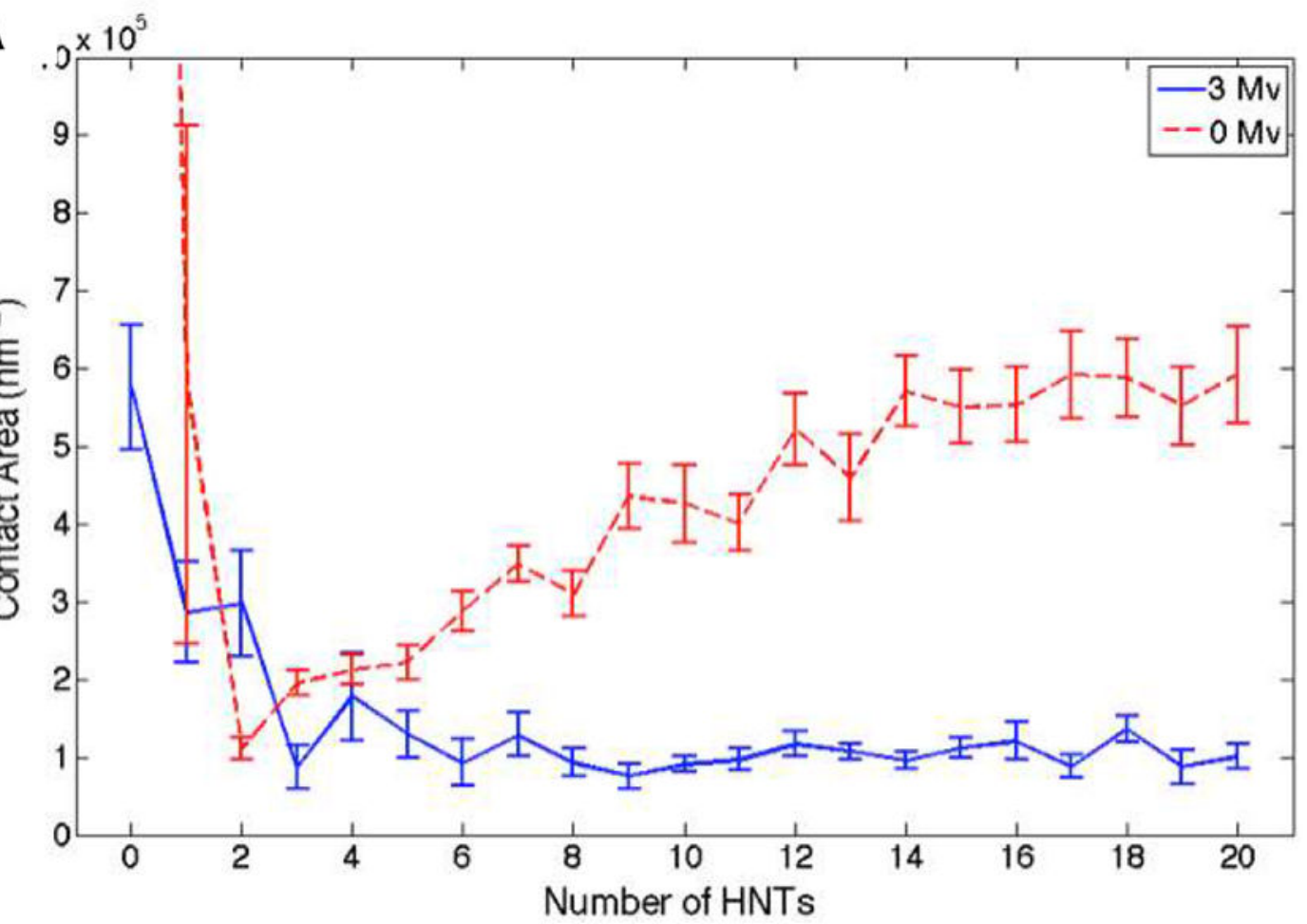

B

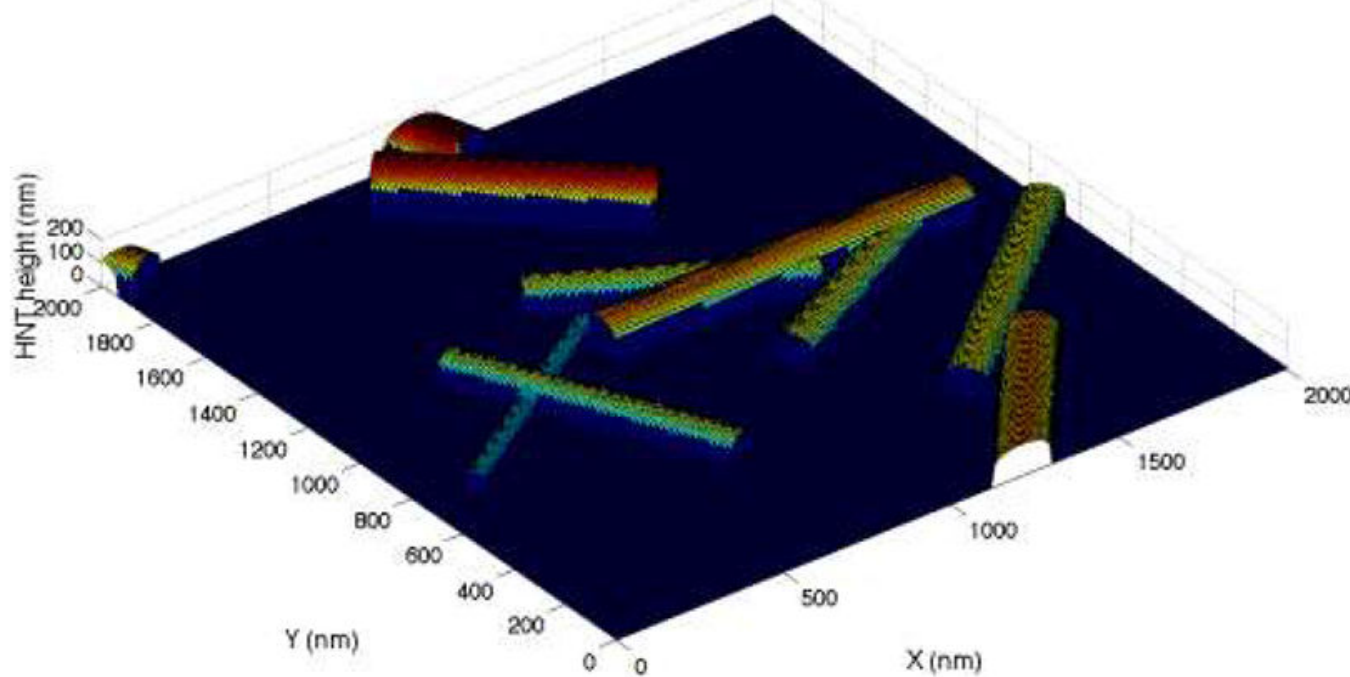

Figure 6.

Computational modeling of a leukocyte interacting with surfaces coated with different numbers of HNt demonstrates that leukocytes, distinct in their expression of microvilli (Mv) maintain a low molecular contact area, or area of direct physical contact, with the surface (3 $\mathrm{Mv}$, blue solid line) compared to a smooth cell ( $0 \mathrm{Mv}$, red dashed line) despite increasing numbers of HNt (A). HNt were generated based on random distributions of length, diameter, location, and orientation on the surface (B). 

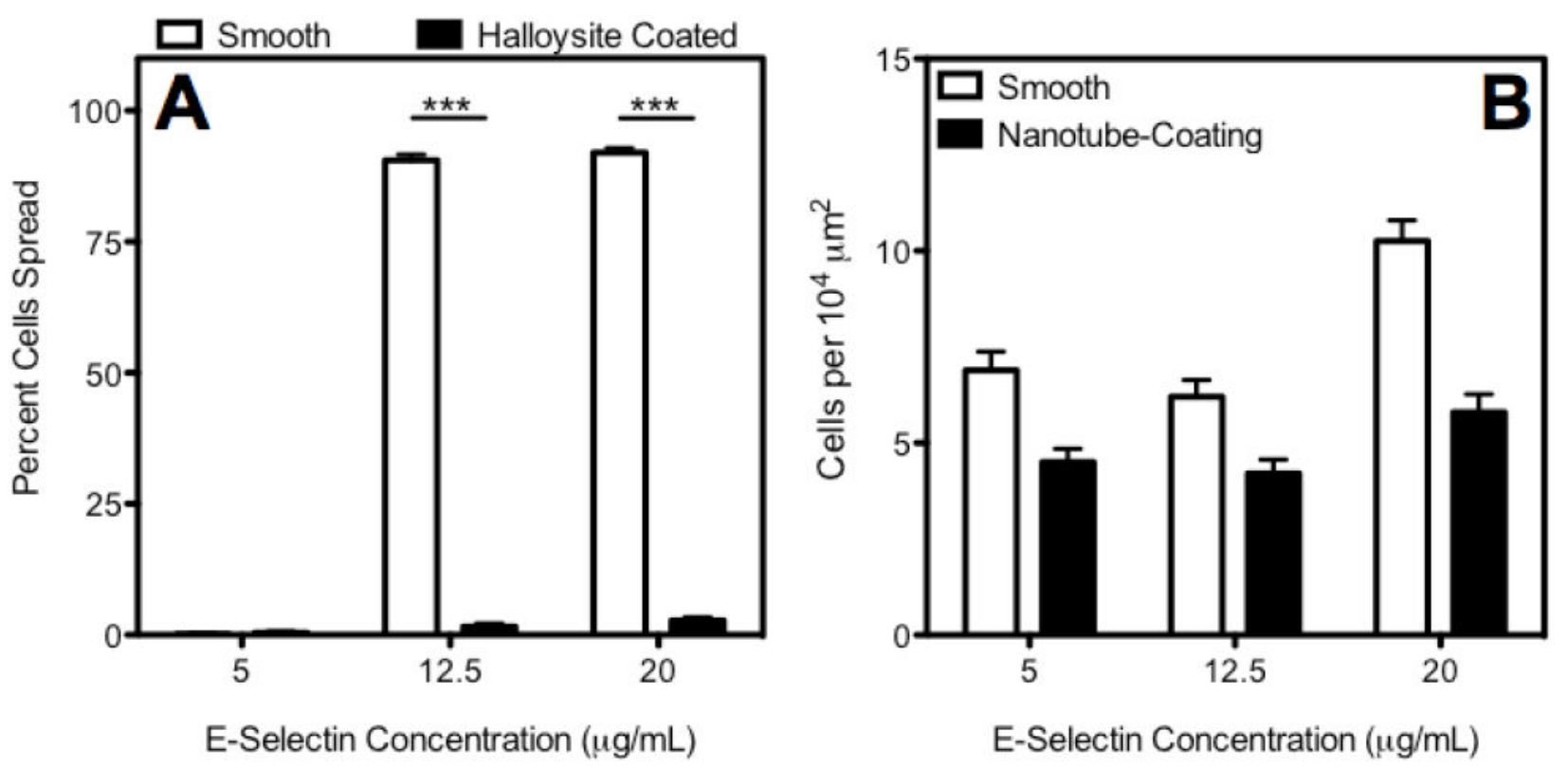

Figure 7.

Leukocyte spreading is absent within a microfluidic device at low surface concentrations of E-selectin and high concentrations of E-selectin in the presence of the HNt coating (A).

Additionally, total leukocyte adhesion is reduced on HNt coatings at all surface concentrations of E-selectin within the flow device (B). 
Table I

Additional surface roughness characteristics of HNt coatings. The Area Ratio is a ratio of surface area to planar area.

\begin{tabular}{ccc}
\hline \% HNT & $\mathbf{R}_{\mathbf{a}}(\mathbf{n m})$ & Area Ratio \\
\hline 13.2 & 146 & 1.267 \\
6.60 & 119 & 1.321 \\
3.30 & 131 & 1.251 \\
1.65 & 166 & 1.264 \\
0.825 & 137 & 1.288 \\
0.413 & 101 & 1.265 \\
0.206 & 81 & 1.163 \\
0 & 5.3 & 1.00 \\
\hline
\end{tabular}

를

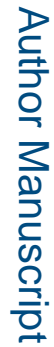

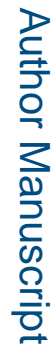

Langmuir. Author manuscript; available in PMC 2016 November 05. 


\section{Table II}

Mean number of distinct peaks in random $2 \mu \mathrm{m}$ segments within AFM images was used to estimate the number of HNt within $2 \mu \mathrm{m} \times 2 \mu \mathrm{m}$ areas (number of peaks squared) for comparison to computational modeling of leukocyte adhesion. SD: standard deviation.

\begin{tabular}{cccc}
\hline \% HNt & \# Peaks & SD & (\# Peaks) $^{2}$ \\
\hline 0.206 & 0.411 & 0.890 & 0.169 \\
0.413 & 0.768 & 0.831 & 0.590 \\
0.825 & 1.16 & 0.949 & 1.35 \\
1.65 & 2.00 & 1.38 & 4.00 \\
3.3 & 3.59 & 1.17 & 12.9 \\
6.6 & 3.54 & 1.33 & 12.5 \\
13.2 & 4.11 & 1.52 & 16.9 \\
\hline
\end{tabular}

